\title{
A Randomized, Double-Blind, Placebo-Controlled, Trial of Lamotrigine Therapy in Bipolar Disorder, Depressed or Mixed Phase and Cocaine Dependence
}

\author{
E Sherwood Brown*,', Prabha Sunderajan', Lisa T Hu', Sharon M Sowell' and Thomas J Carmody' \\ 'Department of Psychiatry, The University of Texas Southwestem Medical Center, Dallas, TX, USA
}

\begin{abstract}
Bipolar disorder is associated with very high rates of substance dependence. Cocaine use is particularly common. However, limited data are available on the treatment of this population. A I0-week, randomized, double-blind, placebo-controlled trial of lamotrigine was conducted in 120 outpatients with bipolar disorder, depressed or mixed mood state, and cocaine dependence. Other substance use was not exclusionary. Cocaine use was quantified weekly by urine drug screens and participant report using the timeline follow-back method. Mood was assessed with the Hamilton rating scale for depression, quick inventory of depressive symptomatology self-report, and young mania rating scale. Cocaine craving was assessed with the cocaine-craving questionnaire. Data were analyzed using a random regression analysis that used all available data from participants with at least one postbaseline assessment $(n=1 \mid 2)$. Lamotrigine and placebo groups were similar demographically (age $45.1 \pm 7.3$ vs $43.5 \pm 10.0$ years, $41.8 \%$ vs $38.6 \%$ women). Urine drug screens (primary outcome measure) and mood symptoms were not significantly different between groups. However, dollars spent on cocaine showed a significant initial (baseline to week I, $p=0.01$ ) and by-week (weeks I-10, $p=0.05$ ) decrease in dollars spent on cocaine, favoring lamotrigine. Few positive trials of medications for cocaine use, other than stimulant replacement, have been reported, and none have been reported for bipolar disorder. Reduction in amount of cocaine use by self-report with lamotrigine suggests that a standard treatment for bipolar disorder may reduce cocaine use. A study limitation was weekly assessment of urine drug screens that decreased the ability to detect between-group differences.
\end{abstract}

Neuropsychopharmacology (2012) 37, 2347-2354; doi:I0. I038/npp.20 I2.90; published online 6 June 2012

Keywords: lamotrigine; bipolar disorder; cocaine dependence; clinical trial

\section{INTRODUCTION}

Bipolar disorders are common, severe, and persistent illnesses affecting about $1.7-2.4 \%$ of the population (Kessler et al, 1994; Merikangas et al, 2011). Substance abuse is common in persons with bipolar disorder (Regier et al, 1990). Regier et al (1990) found a $61 \%$ lifetime prevalence of substance abuse in bipolar I disorder and $48 \%$ in bipolar II disorder. Abuse of and dependence on stimulants, such as cocaine, is especially common in people with bipolar disorder. Miller et al (1989) found 10\% of hospitalized patients with bipolar disorder currently met criteria for a cocaine-use disorder. Mueser et al (1992) reported a lifetime prevalence of stimulant abuse of $34 \%$ among inpatients with bipolar disorder. Polysubstance abuse is also very common

*Correspondence: Dr ES Brown, Department of Psychiatry, The University of Texas Southwestern Medical Center at Dallas, 5323 Harry Hines Blvd., MC 8849, Dallas, Texas 75390-8849, USA,

Tel: + | 214645 6950, Fax: + | 214-645-6951,

E-mail: Sherwood.Brown@UTSouthwestern.edu

Received 6 January 2012; revised 23 April 2012; accepted 30 April 2012 in patients with bipolar disorder (Brown, 2005) with rates of 6-44\% reported (Albanese and Pies, 2004; Estroff et al, 1985; Sonne et al, 1994). Another common comorbidity in patients with bipolar disorder is anxiety disorders. Anxiety disorders and substance use disorders occur together in about $15 \%$ of patients with bipolar disorder (Bauer et al, 2005). We previously reported high rates of anxiety disorders in patients enrolled in clinical trials for bipolar disorder and cocaine or alcohol use disorders (Mitchell et al, 2007). In this sample, PTSD was significantly more common in patients with bipolar disorder and cocaine use than patients with bipolar disorder and alcohol use, whereas the opposite was observed for generalized anxiety disorder.

Cocaine abuse or dependence in persons with bipolar disorder may be more severe and treatment refractory than in the general population. Using the general behavior inventory to screen for mood disorders among patients with psychoactive substance dependence, Saxon et al (1994) reported that bipolar disorder was associated with significantly more lifetime months of cocaine abuse and greater drug use during treatment when compared with patients without this illness. In addition, substance abuse 
may be associated with more hospitalizations and a poor response to lithium compared with patients with bipolar disorder not using these drugs (Aagaard and Vestergaard, 1990; Nunes et al, 1990; Sonne et al, 1994).

Persons with bipolar disorder and cocaine dependence represent a relatively unstudied but particularly challenging population for mental health professionals. Therefore, information about this population is of great importance. Minimal data are available on the pharmacotherapy of patients with bipolar disorder and cocaine dependence (Brown, 2005). Brady et al (2002) found significant reductions in cocaine use by cocaine-dependent individuals with affective disorders $(n=57)$ but not in a group without affective illness $(n=82)$. Brown et al randomized outpatients $(n=29)$ with major mental illness (13 had bipolar I disorder), and cocaine or amphetamine use disorders, who were receiving traditional neuroleptics to either continue therapy the neuroleptic or switch to open-label quetiapine using an overlap and taper method (Brown et al, 2003b). The participants who switched to quetiapine had a significantly greater improvement in mood symptoms and cocaine craving than the treatment-as-usual group. In a more recent report, Brown et al (2002) randomized 12 outpatients with bipolar disorder and cocaine dependence to 12 weeks of quetiapine or placebo. No significant between-group differences were observed, although change in depressive symptoms favored quetiapine with a large effect size, and quetiapine was associated with a trend toward longer time in treatment. Brown et al (2007) reported that citicoline was associated with significantly greater likelihood of a cocaine-negative urine at study exit and improvement in aspects of declarative memory in outpatients $(n=44)$ with bipolar disorder and cocaine dependence. Nejtek et al (2008) compared quetiapine and risperidone in outpatients $(n=124)$ with bipolar disorder and cocaine or methamphetamine use and found that both treatments were associated with improvement in mood and reduced craving, but no significant between-group differences were observed.

Open-label trials in bipolar disorder and cocaine dependence have also been conducted with divalproex (Salloum et al, 2007), quetiapine (Brown et al, 2003b), and lamotrigine (Brown et al, 2003a). An open-label lamotrigine study observed improvement in both manic and depressive symptoms, as well as a decrease in dollars spent on cocaine but not in days of cocaine use (Brown et al, 2003a). In patients with cocaine dependence, but not bipolar disorder, an open-label study of lamotrigine reported an $85 \%$ reduction in cocaine use (Margolin et al, 1998). However, a small, controlled trial ( $n=15$ /group) found no advantage with lamotrigine as compared with placebo on cocainepositive urines (Berger et al, 2005).

Lamotrigine appears to be useful for depressive symptoms and relapse prevention in bipolar disorder (Calabrese et al, 1999, 2000, 2002). Lamotrigine inhibits the release of glutamate through modulation of high voltage-activated calcium currents (Pisani et al, 2004; Stefani et al, 1997; Wang et al, 2001) and sodium channels (Sitges et al, 2007; Stefani et al, 1997). Six recent reviews noted the potential of modulators of glutamate as targets for cocaine use (Gass and Olive, 2008; Javitt et al, 2011; Kalivas and Volkow, 2011; Schmidt and Pierce, 2010; Uys and LaLumiere, 2008; Uys and Reissner, 2011). Medications that decrease glutamate release are potential neuroprotective agents that may decrease cerebral ischemia with cocaine dependence (Kosten, 1998). Interest has also focused on anticonvulsants for addiction owing to the possibility that kindling-like processes may contribute to drug use (Minozzi et al, 2008).

Given a strong mechanistic basis and open-label data suggesting a reduction in cocaine use in patients with bipolar disorder given lamotrigine, a placebo-controlled trial was conducted. The aims of the study were to determine the impact of lamotrigine therapy on cocaine use (primary aim) and cocaine craving, as well as manic and depressive symptoms (secondary aims). The primary outcome measure was urine drug screens with days and dollars spent on cocaine as secondary outcome measures of cocaine use.

\section{MATERIALS AND METHODS}

A total of 120 adult outpatients with bipolar I, II, NOS or cyclothymic disorders, and current cocaine dependence were recruited from local referral sources and newspaper advertisements for the 10-week randomized, double-blind (1:1 ratio of active medication to placebo) study. After complete description of the study to the subjects, IRBapproved, written informed consent was obtained. After obtaining consent, baseline assessment measures were administered including the structured clinical interview for DSM-IV clinician version (SCID-CV) (First et al, 1995). Consent was obtained and all study visits were conducted at our outpatient research clinic located in the UT Southwestern Medical Center.

Inclusion criteria were men or women aged 18-70 years, diagnosis of bipolar I, II, or NOS disorders currently depressed or mixed mood as determined by SCID-CV, current cocaine dependence with self-reported cocaine use within 14 days before randomization, English or Spanish speaking, and baseline Hamilton rating scale for depression 17 -item version $\left(\mathrm{HRSD}_{17}\right)$ score $\geqslant 10$. Excluded were those currently taking an enzyme inducing or inhibiting anticonvulsant (eg, valproic acid, carbamazepine), currently experiencing severe psychotic features (eg, daily auditory hallucinations, fixed delusions, severely disorganized thought processes) that require antipsychotic therapy, and that do not appear to be secondary to cocaine use, active suicidal ideation (plan and intent) or $\geqslant 2$ attempts in past 12 months or any attempt in the last month, highly unstable medical condition, change in concomitant psychiatric medications (eg, initiated antipsychotic) or in other substance abuse treatment (eg, began intensive outpatient treatment) within 7 days before study entry, and vulnerable populations (eg, pregnant or nursing women, incarcerated, or cognitively impaired individuals). Potential participants dependent on substances in addition to cocaine were not excluded.

Drug use was assessed at weekly visits using the timeline follow-back (TLFB) method to quantify days and amount of drug use (Fals-Stewart et al, 2000) and craving was assessed with the cocaine craving questionnaire (Tiffany et al, 1993). Urine drug screens were obtained each week. The total number of days of reported cocaine use, by TLFB, since the last visit was divided by the number of days since the last visit to determine the percent of days of cocaine use per 
week since the last visit. The total amount spent on cocaine since the last visit was divided by the number of days since the last visit to determine the mean amount spent on cocaine per day since the last visit. Mood symptoms were quantified weekly with the $\mathrm{HRSD}_{17}$ (Hamilton, 1960), quick inventory of depressive symptomatology-SR (QIDS-SR) (Rush et al, 2003), and young mania rating scale (YMRS) (Young et al, 1978). The psychobiology of recovery in depression III - somatic symptom scale (PRD-III) is a 24item side effects rating scale developed for longitudinal depression studies (Thase et al, 1996). It covers a wide range of common medication side effects (eg, dizziness, diarrhea, somnolence) and can be quickly and easily administered by a clinician (Thase et al, 1996). It was administered every 2 weeks to track side effects. The items are scored on a threepoint scale and reflect patient perception of the symptom severity. We have previously used this scale in clinical trials for bipolar disorder and substance dependence (Brown et al, 2007, 2009).

The study drug was added to existing psychiatric medications, when present, or given as monotherapy when participants were not taking other medications at baseline. Lamotrigine therapy was initiated at $25 \mathrm{mg} /$ day and increased to $200 \mathrm{mg}$ /day using a slow upward titration over 5 weeks, as outlined by Calabrese et al (2000), to minimize risk of rash. After that time additional increases in $100 \mathrm{mg} /$ day increments to a maximum of $400 \mathrm{mg} /$ day were made if the medication was well tolerated and the following signs of poor response were noted: $\mathrm{HRSD}_{17}$ scores had decreased by $\leqslant 40 \%$ from baseline, CCQ scores had decreased $\leqslant 25 \%$ from baseline, and participants continued to use cocaine in the past week based on either TLFB or urine drug screens. Participants were paid for participation. Concomitant medications were managed with an algorithm, adapted from Bauer et al (2001) that, if necessary, allowed changes in other psychiatric medications. Study enrollment concluded, as planned, after enrollment of 120 participants. The study was registered at ClinicalTrials.gov (NCT00280293).

\section{Statistical Methods}

The number of subjects available for analysis was 112 (those with at least one postbaseline assessment). Of these, 55 received lamotrigine and 57 received placebo. The study was powered for cocaine use based on our pilot data from an open-label trial of lamotrigine and using the placebo group in a literature trial (Brown et al, 2003a). A sample size of 120 is sufficient to detect between-groups differences with a Cohen's $d$ of approximately $\geqslant 0.5$ (medium effect size). Randomization was conducted by the study statistician (TJC) through a computerized randomization process, which was downloaded to a spread-sheet used by unblinded clinic staff to allocate medication. All direct care staff (ie, study physicians and raters) were blinded.

Data were analyzed using a declining effects randomregression model (Kashner et al, 2003) where the treatment effect was divided into an initial period effect as measured by the change from the initiation of treatment at baseline to the first visit (week 1) and a subsequent time trend treatment effect as measured by the change from week 1 to week 12. The initial treatment effect was estimated separately from the subsequent time trend treatment effect because the initial effect may relate primarily to the nonspecific effects of entering a cocaine treatment study and may be different with regard to size and direction from the time trend effect, which may more accurately reflect the effects of treatment. The division into two parts is done because treatment effect is frequently not constant over the course of the trial. If two distinct types of effects are present (initial effect and subsequent time trend effect), a model that allows for estimation of these effects will be more informative and better fitting than a model that does. Also, basing the initial effect on the change to the first measurement occasion means the maximum number of observations is available to estimate the subsequent time trend. Note that randomization does not have an effect on this nonconstant nature of treatment effect. All models included terms for time, treatment group, treatment group by time interaction, the baseline value of the outcome, and type of bipolar disorder (BP I vs other). Sample heterogeneity, potential baseline differences between-groups, and concomitant medication use were controlled by the use of covariates. A comprehensive list of additional baseline variables were considered as covariates to account for sample heterogeneity in demographic and clinical characteristics, substance use, concomitant medication use, anxiety disorder, and mood state as follows: age, gender, race, education level, income, family history of psychiatric illness, current psychiatric treatment, concomitant medication use (total number of concomitant meds, number of anticonvulsants, number of antipsychotics, number of antidepressants, lithium, number of sedatives/hypnotics), number of drinks, number of drinking days, number of heavy drinking days, current mood state, change in medication status during study (no change in meds, med increase during study, med decrease during study), percent days of cocaine use per week, amount spent on cocaine per week, HRSD, CCQ, YMRS, and scores from a baseline neuropsychological battery that included the Rey auditory verbal learning test and Stroop color word test. Each covariate was tested individually along with the covariate by time, covariate by treatment group, and covariate by time by treatment group interactions. A covariate (along with possible interaction terms) was selected if including the terms resulted in a significant maximum likelihood ratio test (ie, significantly improved the model's goodness of fit). All individually significant covariate terms were included together in a model and terms, which lost significance at this point were excluded from the final model. Thus, different outcome measures used different covariates. Covariates were selected without regard to whether they improved the significance of the treatment effect. No adjustment was made for multiple testing because it is preferable to err on the side of including unimportant covariates than to leave out important covariates. For continuous outcomes SAS Proc Mixed was used, and for binary outcomes (cocaine positive urine) SAS Proc GLIMMIX was used.

\section{RESULTS}

Table 1 shows the demographic and baseline characteristics of the two treatment groups. The lamotrigine and placebo 
Table I Baseline Demographic and Clinical Characteristics of Lamotrigine and Placebo Groups (Intent-to-Treat Sample, $N=\mid 12)$

\begin{tabular}{l}
$\begin{array}{l}\text { Baseline } \\
\text { characteristic }\end{array}$ \\
\hline Age in years, mean (SD) \\
Gender, N (\%) \\
Female \\
Male \\
Ethnicity, N (\%) \\
Caucasian \\
African-American \\
Hispanic \\
Asian-Pacific islander/other \\
Income, N (\%) \\
$<\$ 15000$ \\
$\geqslant \$ 15000$
\end{tabular}

Education in years, mean (SD)

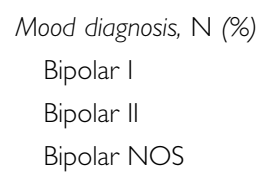

$7(12.7)$

$0(0.0)$

$\begin{array}{cc}17(30.9) & 17(29.8) \\ 34(61.8) & 36(63.2) \\ 3(5.5) & 3(5.3) \\ 1(1.8) & 1(1.8)\end{array}$

$33(60.0)$

$22(40.0)$

$13.5(2.2)$

$30(54.5)$

$21(38.2)$

$4(7.3)$

$38(69.1)$

$14(25.5)$

$3(5.5)$

$33(57.9)$

$24(42.1)$

$13.5(2.4)$

$29(50.9)$

$21(36.8)$

$7(12.3)$

$52(91.2)$

$5(8.8)$

$40(70.2)$

$15(26.3)$

2 (3.5)
Current
Past

Other substance dependence

Current

Past

$2(3.5)$

$3(5.3)$

$0(0.0)$

$9(16.4)$

$0(0.0)$

$10(17.5)$

$4(7.0)$

$9(15.8)$

$0(0.0)$

Other substance abuse

Anxiety disorders, N (\%)

Post-traumatic stress disorder

Panic disorder with agoraphobia

Past
Table I Continued

\begin{tabular}{|c|c|c|}
\hline $\begin{array}{l}\text { Baseline } \\
\text { characteristic }\end{array}$ & $\begin{array}{l}\text { Lamotrigine } \\
\quad(N=55)\end{array}$ & $\begin{array}{l}\text { Placebo } \\
(N=57)\end{array}$ \\
\hline \multicolumn{3}{|c|}{ Amphetamine dependence } \\
\hline Current & $3(5.5)$ & $4(7.0)$ \\
\hline Past & $5(9.1)$ & $6(10.5)$ \\
\hline \multicolumn{3}{|c|}{ Amphetamine abuse } \\
\hline Current & $0(0.0)$ & $0(0.0)$ \\
\hline Past & $0(0.0)$ & । (।.8) \\
\hline \multicolumn{3}{|c|}{ Opioid dependence } \\
\hline Current & $3(5.5)$ & $6(10.5)$ \\
\hline Past & । (।.8) & $0(0.0)$ \\
\hline \multicolumn{3}{|l|}{ Opioid abuse } \\
\hline Current & $0(0.0)$ & $2(3.5)$ \\
\hline Past & $0(0.0)$ & $0(0.0)$ \\
\hline \multicolumn{3}{|c|}{ Hallucinogen dependence } \\
\hline Current & । ( 1.8$)$ & $2(3.5)$ \\
\hline Past & । ( $(1.8)$ & $2(3.5)$ \\
\hline \multicolumn{3}{|c|}{ Hallucinogen abuse } \\
\hline Current & $0(0.0)$ & $0(0.0)$ \\
\hline Past & $0(0.0)$ & $0(0.0)$ \\
\hline \multicolumn{3}{|c|}{ Sedative/hypnoticlanxiolytic } \\
\hline Current & $0(0.0)$ & $2(3.5)$ \\
\hline Past & । ( $(1.8)$ & $0(0.0)$ \\
\hline \multicolumn{3}{|c|}{ Sedative/hypnotic/anxiolytic abuse } \\
\hline Current & $0(0.0)$ & । ( $(.8)$ \\
\hline Past & । ( 1.8$)$ & $0(0.0)$ \\
\hline
\end{tabular}

$0(0.0) \quad 0(0.0)$

I (I.8) $\quad 0(0.0)$

$\begin{array}{lll}\text { Current } & 0(0.0) & 0(0.0) \\ \text { Past } & 1(1.8) & 0(0.0)\end{array}$

$\begin{array}{lll}\text { Current } & 6(10.9) & 5(8.8) \\ \text { Past } & 5(9.1) & 4(7.0)\end{array}$

Current I (I.8)


Table I Continued

\begin{tabular}{|c|c|c|}
\hline $\begin{array}{l}\text { Baseline } \\
\text { characteristic }\end{array}$ & $\begin{array}{l}\text { Lamotrigine } \\
\quad(N=55)\end{array}$ & $\begin{array}{l}\text { Placebo } \\
(N=57)\end{array}$ \\
\hline \multicolumn{3}{|c|}{ Panic disorder without agoraphobia } \\
\hline Current & $2(3.6)$ & $0(0.0)$ \\
\hline Past & $7(\mid 2.7)$ & $2(3.5)$ \\
\hline \multicolumn{3}{|c|}{ Agoraphobia without panic disorder } \\
\hline Current & $2(3.6)$ & I ( 1.8$)$ \\
\hline Past & । (।.8) & $0(0.0)$ \\
\hline \multicolumn{3}{|c|}{ Generalized anxiety disorder } \\
\hline Current & $6(10.9)$ & $0(0.0)$ \\
\hline Past & । ( 1.8$)$ & $0(0.0)$ \\
\hline \multicolumn{3}{|l|}{ Specific phobia } \\
\hline Current & $3(5.5)$ & $2(3.5)$ \\
\hline Past & $0(0.0)$ & I ( $(1.8)$ \\
\hline \multicolumn{3}{|c|}{ Obsessive compulsive disorder } \\
\hline Current & । ( 1.8$)$ & $0(0.0)$ \\
\hline Past & $2(3.6)$ & $0(0.0)$ \\
\hline \multicolumn{3}{|l|}{ Social phobia } \\
\hline Current & $2(3.6)$ & $0(0.0)$ \\
\hline Past & $0(0.0)$ & । ( $(1.8)$ \\
\hline \multicolumn{3}{|c|}{ Anxiety disorder NOS } \\
\hline Current & । ( 1.8$)$ & $0(0.0)$ \\
\hline Past & $0(0.0)$ & $0(0.0)$ \\
\hline
\end{tabular}

groups were similar demographically (age $45.1 \pm 7.3$ vs $43.5 \pm 10.0$ years, $41.8 \%$ vs $38.6 \%$ women, $54.5 \%$ vs $50.9 \%$ bipolar I, $89.1 \%$ vs $91.2 \%$ depressed). Many of the participants used substances in addition to cocaine. Anxiety disorders were also common. The mean exit dose of lamotrigine was $221.8 \pm 148.0 \mathrm{mg}$ in the active medication group and pills dispensed equivalent to $192.1 \pm 146.8 \mathrm{mg}$ in the placebo group. Adherence, based on pills dispensed and returned, was $92 \%$ with lamotrigine and $93 \%$ with placebo. However, at $8 \%$ of appointments with lamotrigine and $7 \%$ with placebo, participants did not return the unused pills. In addition, participants were no shows for $9 \%$ of appointments with lamotrigine and $12 \%$ for placebo. These missing data were not included in the pill count adherence estimate. Because failure to return unused pills and missing appointments could be signs of medication nonadherence, actual medication adherence may have been lower than the above estimate. No participants were receiving intensive outpatient therapy for substance use. Some participants were taking concomitant psychiatric medications at baseline. These medications were lithium $(n=1)$, antidepressants $(n=10)$, antipsychotics $(n=2)$, and sedative/hypnotic/anxiolytics $(n=5)$ in the lamotrigine group and lithium $(n=6)$, antidepressants $(n=10)$, antipsychotics $(n=2)$, and sedative/hypnotic/anxiolytics $(n=4)$ in the placebo group.
Table 2 Results of Between-Groups Analysis $(N=|| 2)$

\begin{tabular}{|c|c|c|}
\hline Outcome measures & F-value & Significance ( $p$-value) \\
\hline \multicolumn{3}{|l|}{ Cocaine use (probability of +UDS) } \\
\hline Initial effect: weeks $0-1$ & $F(1,1 \mid 3)=1.1$ & 0.30 \\
\hline By week effect: weeks $1-10$ & $F(I, 80)=0.0$ & 0.99 \\
\hline \multicolumn{3}{|l|}{ Percent days used cocaine } \\
\hline Initial effect: weeks $0-1$ & $F(I, 147)=2.5$ & 0.12 \\
\hline By week effect: weeks $1-10$ & $F(1,96)=1.1$ & 0.31 \\
\hline \multicolumn{3}{|l|}{ Dollar amount spent on cocaine } \\
\hline Initial effect: weeks 0-I & $F(1,93)=11.2$ & 0.01 \\
\hline By week effect: weeks I-10 & $F(1,62)=3.9$ & 0.05 \\
\hline \multicolumn{3}{|l|}{ Cocaine craving questionnaire } \\
\hline Initial effect: weeks $0-\mid$ & $F(1,100)=1.3$ & 0.26 \\
\hline By week effect: weeks $1-10$ & $F(I, 83)=0.4$ & 0.53 \\
\hline \multicolumn{3}{|l|}{ HRSD (depression scale rating) } \\
\hline Initial effect: weeks 0-I & $F(1,104)=0.6$ & 0.44 \\
\hline BY week effect: weeks I-10 & $F(I, 79)=0.3$ & 0.57 \\
\hline \multicolumn{3}{|l|}{ QIDS-SR (self-rated depression) } \\
\hline Initial effect: weeks $0-\mid$ & $t(106)=0.0$ & 0.97 \\
\hline By week effect: weeks 1-10 & $t(77)=0.1$ & 0.89 \\
\hline \multicolumn{3}{|l|}{ YMRS (mania) } \\
\hline Initial effect: weeks 0-I & $F(I, \mid 74)=0.3$ & 0.56 \\
\hline By week effect: weeks $1-10$ & $F(I, 190)=0.5$ & 0.47 \\
\hline \multicolumn{3}{|l|}{ PRD-III score (repeated measures) } \\
\hline Initial effect: weeks 0-I & $F(I, 93)=0.5$ & 0.49 \\
\hline By week effect: weeks $1-10$ & $F(I, 7 I)=1.3$ & 0.26 \\
\hline
\end{tabular}

Results of the random regression analyses are given in Table 2. Percentage of cocaine-positive urine drug screens (baseline covariates: bipolar type, sedative/hypnotic use, days of alcohol use) and CCQ scores, (baseline covariates: bipolar type, HRSD scores, income) did not differ between groups. The relative risk was 1.67 at week 1 and 1.72 at week 10 with those taking lamotrigine nonsignificantly more likely to be cocaine-negative than those taking placebo. However, dollars spent on cocaine (baseline covariates: bipolar type, sedative/hypnotic use, cocaine use, Stroop color word scores, CCQ score) showed a significant between-group difference on both initial $(p=0.01)$ and by-week effect $(p=0.05)$.

Scores on the QIDS-SR (baseline covariates: bipolar type, anxiety disorder diagnosis), HRSD (baseline covariates: bipolar type), YMRS (baseline covariates: bipolar type, age, gender, income, previous psychological treatment), and PRD-III (baseline covariates: bipolar type, RAVLT total score) were not significantly different between groups in the sample as a whole. 
Although between-group differences in mood were not observed, improvement in cocaine use observed in both treatment groups could be due, at least in part, to improvement in mood symptoms. Therefore, we conducted a post hoc analysis of cocaine use including mood as a timevarying covariate. Adding this covariate allowed us to estimate the treatment effect as if mood were held constant during the study. Thus, we could estimate change over time in cocaine use that was independent of mood. When the HRSD was included as a time-varying covariate in the analysis of amount spent on cocaine per week we found that HRSD was a significant covariate $(p<0.0001)$. The initial treatment effect remained significant $(p=0.03$ rather than $p=0.01$ without the time-varying covariate) but the time effect lost its significance $(p=0.01$ in the original analysis but $p=0.08$ with the HRSD added), as did the time by treatment group interaction ( $p=0.05$ in the original analysis but $p=0.08$ with HRSD added). YMRS was also a significant covariate $(p=0.002)$ for amount spent on cocaine per week. The initial treatment effect remained significant $(p=0.02$ rather than $p=0.01$ without the time-varying covariate). The time effect was still significant $(p=0.01$ in the original analysis, $p=0.004$ with the YMRS added). The time by treatment group interaction lost its significance ( $p=0.05$ in the original analysis but $p=0.07$ with YMRS added). Baseline to exit change in HRSD scores correlated significantly with change in days of cocaine use in the combined treatment groups $(r=0.29, p=0.002)$, as well as those in the lamotrigine $(r=0.30, p=0.03)$ and placebo groups $(r=0.28, p=0.04)$, and change in CCQ scores in the combined $(r=0.45, \quad p<0.0001)$, lamotrigine $(r=0.50$, $p=0.0002)$ and placebo groups $(r=0.42, p=0.001)$. Change in amount spent on cocaine did not correlate significantly with changes in HRSD scores. Changes in YMRS scores correlated significantly with changes in days of cocaine use in the combined group $(r=0.19, p=0.05)$ and with change in the CCQ in the combined $(r=0.23, p=0.02)$ and placebo groups $(r=0.30, p=0.02)$.

The literature suggested that lamotrigine has efficacy for the treatment of bipolar depression only in patients with baseline HRSD scores $>24$ (Geddes et al, 2009). Therefore, we conducted a post-hoc analysis of this subgroup and found a trend favoring lamotrigine for the YMRS $(n=36$, initial effect: $\mathrm{F}(1,42)=2.7, p=0.11$, by week effect: $\mathrm{F}(1$, $50)=3.2, p=0.08)$ but no difference was observed for the HRSD $(n=40$, initial effect: $\mathrm{F}(1,33)=0.08, p=0.78$, by week effect: $\mathrm{F}(1,20)=0.02, p=0.88)$ or QIDS-SR $(n=40$, initial effect: $\mathrm{F}(1,35)=0.82, p=0.37$, by week effect: $\mathrm{F}(1,24)=0.22, p=0.64)$.

Survival in the study was similar in the two groups. See a Kaplan-Meier Survival Curve in Figure 1. Of the 120 participants enrolled, 63 completed the study. Reasons for discontinuation included: 26 lost to follow-up, 5 moved, 3 withdrew consent, 3 unrelated medical reasons, 1 severe treatment nonadherence, 2 suicidal ideation and 2 suicide attempt, 2 inpatient admissions for unrelated medical conditions, 1 rash that was determined to not be related to lamotrigine, 1 related to a probation violation, 1 due to incarceration, and 2 for other reasons.

Side effects were similar in the two groups. The two treatment conditions were associated with nonsignificantly different levels of somatic complaints as assessed by the
PRD-III somatic symptom scale. Of a total of 17 adverse events reported (10 lamotrigine, 7 placebo), 2 adverse events were considered study-related and included drying and peeling of the skin, and increased sweating (both reported by the same patient on two different visits (lamotrigine group)). A total of 15 additional adverse events were classified as unexpected and unrelated to the study.

\section{DISCUSSION}

To our knowledge, this is the largest clinical trial reported, to date, in patients with bipolar disorder and cocaine dependence and the second largest in patients with bipolar disorder and any substance use disorder. A significantly greater decrease in the amount spent on cocaine by participant report was observed with lamotrigine. Although the percentage of cocaine-positive urines during treatment were smaller with lamotrigine, the findings were not statistically significant. The discrepancy between the reported amount of cocaine use (dollars spent) and the urine drug screens could be due to several factors. The participants may not have given entirely accurate assessments of their use. Although underreporting of substance use is common, two treatment groups that were otherwise similar might be expected to have similar rates of misreporting. Owing to a concern that it would not be feasible to get patients with both bipolar disorder and cocaine dependence to return for thrice weekly urines drug screens, as is customary in cocaine trials, we only obtained weekly urine samples. This design feature decreased our number of observations, and hence statistical power, and did not provide us with a complete picture of cocaine use between weekly visits. Alternatively, lamotrigine could decrease the amount of cocaine use more than the frequency of cocaine use. Consistent with this possibility is observation that dollars spent on cocaine (a measure of amount and frequency) decreased with lamotrigine, whereas days of cocaine use (a measure of frequency of use) did not significantly decrease. Similar findings were reported in an open-label trial of lamotrigine in bipolar disorder and cocaine dependence (Brown et al, 2003a).

The treatment groups did not differ significantly on changes in depressive or manic symptoms. As almost all of the participants were depressed at baseline, the negative results for manic symptoms could be due to the low baseline scores on the YMRS. Prior research suggested that lamotrigine only showed a separation from placebo for the acute treatment of bipolar depression when baseline HRSD scores are $>24$ (Geddes et al, 2009). Therefore, we conducted a post-hoc analysis of this more severely depressed subgroup. This exploratory analysis revealed a significant effect of lamotrigine on manic but not depressive symptoms. The inability to see a difference in depressive symptoms in this subgroup may have been due to the small number of participants with HRSD scores $\geqslant 24$ at baseline. The trend toward a reduction in YMRS scores in this subgroup with greater depressive symptom severity is also interesting. To our knowledge, changes in manic symptoms with lamotrigine in patients with greater depressive symptom severity have not been previously examined. Perhaps the reduction in manic symptoms was, at least in part, related to 


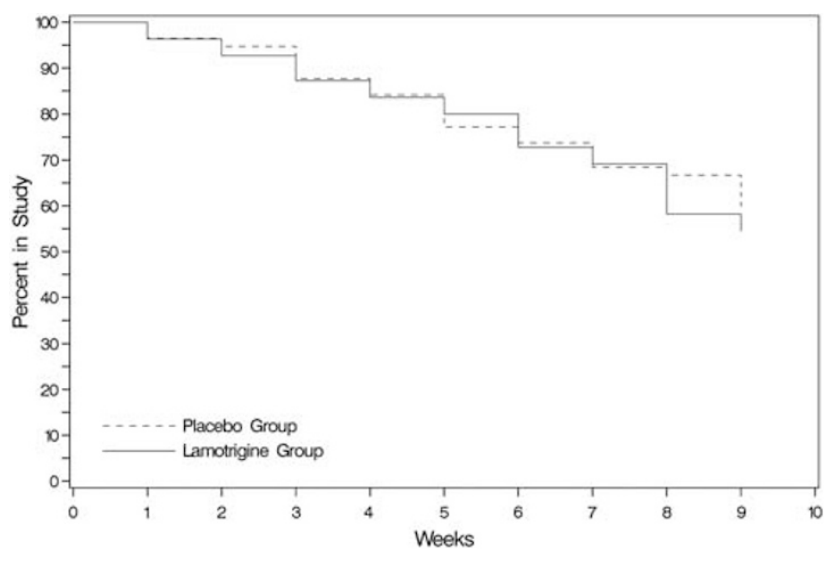

Figure I Kaplan-Meier survival curve for the lamotrigine and placebo groups.

a reduction in the amount of cocaine used. Consistent with this idea was the observation that changes in the YMRS correlated with some cocaine use outcomes. However, the correlations were generally stronger between changes in the HRSD and changes in cocaine use and craving.

Lamotrigine was well tolerated. Side effects were nonsignificantly different in the treatment groups. The two groups had similar retention (Figure 1). Thus, lamotrigine appears to be relatively safe to use in this population.

In summary, lamotrigine appeared to be safe and well tolerated by bipolar disorder patients with active cocaine use. Cocaine use, as measured by amount spent per week, decreased per patient report but not as assessed by urine drug screen. Additional research with lamotrigine using more frequent urine drug screens and a larger patient sample is needed. In addition, because lamotrigine appears to work better in preventing mood symptoms with bipolar disorder than as an acute treatment, trials of lamotrigine for relapse prevention in those with recent cocaine abstinence may be warranted.

\section{ACKNOWLEDGEMENTS}

This study was funded by the Stanley Medical Research Institute, grant number 05T-704. Study drug was provided by GlaxoSmithKline. Neither organization participated in the design, conduct or interpretation of the study.

\section{DISCLOSURE}

Dr Brown would like to disclose funding from the following organizations: Stanley Medical Research Institute, Sunovion Pharmaceuticals, Forest Research Institute, GlaxoSmithKline and AstraZeneca. Dr Sunderajan would like to disclose funding from the following organizations: BristolMyers Squibb, Lilly USA, LLC, and Takeda Pharmaceuticals North America. Dr Carmody would like to disclose the following organizations from which he received consulting fees: Cyberonics and the Institute for Chronic Illness. Ms $\mathrm{Hu}$ and Ms Sowell declare no conflict of interest.

\section{REFERENCES}

Aagaard J, Vestergaard P (1990). Predictors of outcome in prophylactic lithium treatment: a 2-year prospective study. J Affect Disord 18: 259-266.

Albanese MJ, Pies R (2004). The bipolar patient with comorbid substance use disorder: recognition and management. CNS Drugs 18: 585-596.

Bauer MS, Altshuler L, Evans DR, Beresford T, Williford WO, Hauger R (2005). Prevalence and distinct correlates of anxiety, substance, and combined comorbidity in a multi-site public sector sample with bipolar disorder. J Affect Disord 85: 301-315.

Bauer MS, Williford WO, Dawson EE, Akiskal HS, Altshuler L, Fye $\mathrm{C}$ et al (2001). Principles of effectiveness trials and their implementation in VA Cooperative Study \#430: 'reducing the efficacy-effectiveness gap in bipolar disorder'. J Affect Disord 67: 61-78.

Berger SP, Winhusen TM, Somoza EC, Harrer JM, Mezinskis JP, Leiderman DB et al (2005). A medication screening trial evaluation of reserpine, gabapentin and lamotrigine pharmacotherapy of cocaine dependence. Addiction 100(Suppl 1): $58-67$.

Brady KT, Sonne SC, Malcolm RJ, Randall CL, Dansky BS, Simpson $\mathrm{K}$ et al (2002). Carbamazepine in the treatment of cocaine dependence: subtyping by affective disorder. Exp Clin Psychopharmacol 10: 276-285.

Brown ES (2005). Bipolar disorder and substance abuse. Psychiatr Clin North Am 28: 415-425.

Brown ES, Carmody TJ, Schmitz JM, Caetano R, Adinoff B, Swann AC et al (2009). A randomized, double-blind, placebo-controlled pilot study of naltrexone in outpatients with bipolar disorder and alcohol dependence. Alcohol Clin Exp Res 33: 1863-1869.

Brown ES, Gorman AR, Hynan LS (2007). A randomized, placebocontrolled trial of citicoline add-on therapy in outpatients with bipolar disorder and cocaine dependence. J Clin Psychopharmacol 27: 498-502.

Brown ES, Nejtek VA, Perantie DC, Bobadilla L (2002). Quetiapine in bipolar disorder and cocaine dependence. Bipolar Disord 4: 406-411.

Brown ES, Nejtek VA, Perantie DC, Orsulak PJ, Bobadilla L (2003a). Lamotrigine in patients with bipolar disorder and cocaine dependence. J Clin Psychiatry 64: 197-201.

Brown ES, Nejtek VA, Perantie DC, Rajan Thomas N, Rush AJ (2003b). Cocaine and amphetamine use in patients with psychiatric illness: a randomized trial of typical antipsychotic continuation or discontinuation. J Clin Psychopharmacol 23: 384-388.

Calabrese JR, Bowden CL, Sachs GS, Ascher JA, Monaghan E, Rudd GD (1999). A double-blind placebo-controlled study of lamotrigine monotherapy in outpatients with bipolar I depression. Lamictal 602 Study Group. J Clin Psychiatry 60: 79-88.

Calabrese JR, Shelton MD, Rapport DJ, Kimmel SE (2002). Bipolar disorders and the effectiveness of novel anticonvulsants. J Clin Psychiatry 63(Suppl 3): 5-9.

Calabrese JR, Suppes T, Bowden CL, Sachs GS, Swann AC, McElroy SL et al (2000). A double-blind, placebo-controlled, prophylaxis study of lamotrigine in rapid-cycling bipolar disorder. Lamictal 614 Study Group. J Clin Psychiatry 61: 841-850.

Estroff TW, Dackis CA, Gold MS, Pottash AL (1985). Drug abuse and bipolar disorders. Int J Psychiatry Med 15: 37-40.

Fals-Stewart W, O'Farrell TJ, Freitas TT, McFarlin SK, Rutigliano P (2000). The timeline followback reports of psychoactive substance use by drug-abusing patients: psychometric properties. J Consult Clin Psychol 68: 134-144.

First M, Spitzer R, Gibbon M, JBW W (1995). Structured Clinical Interview for DSM-IV Axis I Disorders. Biometrics Research Department, New York State Psychiatric Institute, Department of Psychiatry, Columbia University: New York. 
Gass JT, Olive MF (2008). Glutamatergic substrates of drug addiction and alcoholism. Biochem Pharmacol 75: 218-265.

Geddes JR, Calabrese JR, Goodwin GM (2009). Lamotrigine for treatment of bipolar depression: independent meta-analysis and meta-regression of individual patient data from five randomised trials. Br J Psychiatry 194: 4-9.

Hamilton M (1960). A rating scale for depression. J Neurol Neurosurg Psychiatry 23: 56-62.

Javitt DC, Schoepp D, Kalivas PW, Volkow ND, Zarate C, Merchant $\mathrm{K}$ et al (2011). Translating glutamate: from pathophysiology to treatment. Sci Transl Med 3: 102mr102.

Kalivas PW, Volkow ND (2011). New medications for drug addiction hiding in glutamatergic neuroplasticity. Mol Psychiatry 16: 974-986.

Kashner TM, Carmody TJ, Suppes T, Rush AJ, Crismon ML, Miller $\mathrm{AL}$ et al (2003). Catching up on health outcomes: the Texas Medication Algorithm Project. Health Serv Res 38(1 Pt 1): 311-331.

Kessler RC, McGonagle KA, Zhao S, Nelson CB, Hughes M, Eshleman $S$ et al (1994). Lifetime and 12-month prevalence of DSM-III-R psychiatric disorders in the United States. Results from the National Comorbidity Survey. Arch Gen Psychiatry 51: 8-19.

Kosten TR (1998). Pharmacotherapy of cerebral ischemia in cocaine dependence. Drug Alcohol Depend 49: 133-144.

Margolin A, Avants SK, DePhilippis D, Kosten TR (1998). A preliminary investigation of lamotrigine for cocaine abuse in HIV-seropositive patients. Am J Drug Alcohol Abuse 24: 85-101.

Merikangas KR, Jin R, He JP, Kessler RC, Lee S, Sampson NA et al (2011). Prevalence and correlates of bipolar spectrum disorder in the world mental health survey initiative. Arch Gen Psychiatry 68: $241-251$.

Miller FT, Busch F, Tanenbaum JH (1989). Drug abuse in schizophrenia and bipolar disorder. Am J Drug Alcohol Abuse 15: 291-295.

Minozzi S, Amato L, Davoli M, Farrell M, Lima Reisser AA, Pani PP et al (2008). Anticonvulsants for cocaine dependence. Cochrane Database Syst Rev 16: CD006754.

Mitchell JD, Brown ES, Rush AJ (2007). Comorbid disorders in patients with bipolar disorder and concomitant substance dependence. J Affect Disord 102: 281-287.

Mueser KT, Yarnold PR, Bellack AS (1992). Diagnostic and demographic correlates of substance abuse in schizophrenia and major affective disorder. Acta Psychiatr Scand 85: 48-55.

Nejtek VA, Avila M, Chen LA, Zielinski T, Djokovic M, Podawiltz A et al (2008). Do atypical antipsychotics effectively treat cooccurring bipolar disorder and stimulant dependence? A randomized, double-blind trial. J Clin Psychiatry 69: 1257-1266.

Nunes EV, McGrath PJ, Wager S, Quitkin FM (1990). Lithium treatment for cocaine abusers with bipolar spectrum disorders. Am J Psychiatry 147: 655-657.

Pisani A, Bonsi P, Martella G, De Persis C, Costa C, Pisani F et al (2004). Intracellular calcium increase in epileptiform activity: modulation by levetiracetam and lamotrigine. Epilepsia 45 719-728.

Regier DA, Farmer ME, Rae DS, Locke BZ, Keith SJ, Judd LL et al (1990). Comorbidity of mental disorders with alcohol and other drug abuse. Results from the Epidemiologic Catchment Area (ECA) Study. JAMA 264: 2511-2518.

Rush AJ, Trivedi MH, Ibrahim HM, Carmody TJ, Arnow B, Klein $\mathrm{DN}$ et al (2003). The 16-item quick inventory of depressive symptomatology (QIDS), clinician rating (QIDS-C), and selfreport (QIDS-SR): a psychometric evaluation in patients with chronic major depression. Biol Psychiatry 54: 573-583.

Salloum IM, Douaihy A, Cornelius JR, Kirisci L, Kelly TM, Hayes J (2007). Divalproex utility in bipolar disorder with cooccurring cocaine dependence: a pilot study. Addict Behav 32 $410-415$.

Saxon AJ, Calsyn DA, Stanton V, Hawker CS (1994). Using the general behavior inventory to screen for mood disorders among patients with psychoactive substance dependence. Am J Addict 3: 296-305.

Schmidt HD, Pierce RC (2010). Cocaine-induced neuroadaptations in glutamate transmission: potential therapeutic targets for craving and addiction. Ann NY Acad Sci 1187: 35-75.

Sitges M, Chiu LM, Guarneros A, Nekrassov V (2007). Effects of carbamazepine, phenytoin, lamotrigine, oxcarbazepine, topiramate and vinpocetine on $\mathrm{Na}+$ channel-mediated release of $[3 \mathrm{H}]$ glutamate in hippocampal nerve endings. Neuropharmacology 52: 598-605.

Sonne SC, Brady KT, Morton WA (1994). Substance abuse and bipolar affective disorder. J Nerv Ment Dis 182: 349-352.

Stefani A, Spadoni F, Bernardi G (1997). Differential inhibition by riluzole, lamotrigine, and phenytoin of sodium and calcium currents in cortical neurons: implications for neuroprotective strategies. Exp Neurol 147: 115-122.

Thase ME, Fava M, Halbreich U, Kocsis JH, Koran L, Davidson J et al (1996). A placebo-controlled, randomized clinical trial comparing sertraline and imipramine for the treatment of dysthymia. Arch Gen Psychiatry 53: 777-784.

Tiffany ST, Singleton E, Haertzen CA, Henningfield JE (1993). The development of a cocaine craving questionnaire. Drug Alcohol Depend 34: 19-28.

Uys JD, LaLumiere RT (2008). Glutamate: the new frontier in pharmacotherapy for cocaine addiction. CNS Neurol Disord Drug Targets 7: 482-491.

Uys JD, Reissner KJ (2011). Glutamatergic neuroplasticity in cocaine addiction. Prog Mol Biol Transl Sci 98: 367-400.

Wang SJ, Sihra TS, Gean PW (2001). Lamotrigine inhibition of glutamate release from isolated cerebrocortical nerve terminals (synaptosomes) by suppression of voltage-activated calcium channel activity. Neuroreport 12: 2255-2258.

Young RC, Biggs JT, Ziegler VE, Meyer DA (1978). A rating scale for mania: reliability, validity and sensitivity. Br J Psychiatry 133 $429-435$. 